\title{
Educação 4.0 no ensino militar: utopia ou necessidade?
}

\author{
Education 4.0 in military education: utopia or need? \\ Educación 4.0 en la educación militar: ¿utopía o necesidad?
}

Recebido: 29/07/2021 | Revisado: 02/08/2021 | Aceito: 03/08/2021 | Publicado: 08/08/2021

\author{
Carlos Alberto Schettini Pinto \\ ORCID: https://orcid.org/0000-0001-6674-289X \\ Centro Federal de Educação Tecnológica Celso Suckow da Fonseca, Brasil \\ E-mail: carlos.schettini@aluno.cefet-rj.br \\ Diego de Oliveira da Cunha \\ ORCID: https://orcid.org/0000-0002-0738-046X \\ Centro Federal de Educação Tecnológica Celso Suckow da Fonseca, Brasil \\ E-mail: diego.cunha@aluno.cefet-rj.br \\ Augusto da Cunha Reis \\ ORCID: https://orcid.org/0000-0002-3200-8096 \\ Centro Federal de Educação Tecnológica Celso Suckow da Fonseca, Brasil \\ E-mail: augusto.reis@cefet-ri.br
}

\begin{abstract}
Resumo
O presente trabalho debater conceitualmente a educação 4.0 no escopo da educação militar. É sabido que a atividade militar possui e utiliza diversas tecnologias de ponta, as quais demandam um acurado conhecimento para a sua aplicação. Desta forma não podemos conceber a evolução da educação 4.0 no meio civil sem estender este conhecimento para o ambiente militar. Além disso, a incorporação de procedimentos para a geração, manutenção e perpetuação de conhecimentos é fundamental para que o mesmo não se restrinja a poucos, alcançando aos diversos níveis operacionais da Força Terrestre. É neste fértil terreno que a Gestão do Conhecimento surge como um repositório e um capilarizador de informações.
\end{abstract}

Palavra-chave: Educação 4.0; Educação militar; Indústria 4.0; Gestão do conhecimento; Ensino.

\begin{abstract}
The present work conceptually debates education 4.0 in the scope of military education. It is known that the military activity has and uses several cutting-edge technologies, which demand accurate knowledge for their application. Thus, we cannot conceive the evolution of education 4.0 in the civilian environment without extending this knowledge to the military environment. In addition, the incorporation of procedures for the generation, maintenance and perpetuation of knowledge is fundamental so that it is not restricted to a few, reaching the various operational levels of the Land Force. It is in this fertile terrain that Knowledge Management emerges as a repository and a capillary of information.
\end{abstract}

Keywords: Education 4.0; Military education; Industry 4.0; Knowledge management; Teaching.

\section{Resumen}

El presente trabajo debate conceptualmente la educación 4.0 en el ámbito de la educación militar. Se sabe que la actividad militar cuenta y utiliza varias tecnologías de punta, las cuales exigen conocimientos precisos para su aplicación. Por tanto, no podemos concebir la evolución de la educación 4.0 en el ámbito civil sin extender este conocimiento al ámbito militar. Además, la incorporación de procedimientos para la generación, mantenimiento y perpetuación del conocimiento es fundamental para que no se limite a unos pocos, llegando a los distintos niveles operativos de la Fuerza Terrestre. Es en este terreno fértil donde la Gestión del Conocimiento emerge como repositorio y capilar de información.

Palabras clave: Educación 4.0; Educación militar; Industria 4.0; Conocimiento administrativo; Enseñanza.

\section{Introdução}

A Quarta Revolução Industrial ou Industria 4.0 é um conceito desenvolvido durante a Feira de Ha-nover, em 2011, na Alemanha que vem ocupando espaços nas diversas áreas profissionais, gerando a ne-cessidade de pessoas mais bem formadas e capacitadas a enfrentarem os desafios do mundo conectado, gerando impacto direto na produtividade, uma vez que proporciona significativos aumentos em eficiência no uso dos recursos permitindo a produção em larga escala da cadeia 
produtiva.

Bitkom et al., (2016) citam que a Indústria 4.0 foi um dos termos utilizados para descrever a estraté-gia de alta tecnologia promovida pelo governo alemão que vem sendo implementada por sua indústria, abrangendo um conjunto de tecnologias de ponta ligadas à internet com objetivo de tornar os sistemas de produção mais flexíveis e colaborativos.

$\mathrm{Na}$ esteira da Indústria 4.0 não poderia deixar de haver a preparação e qualificação do capital humano para poder atuar de forma eficiente junto às tecnologias ora disponibilizadas e as que estão sendo desen-volvidas. Neste diapasão surge a necessidade de uma Educação 4.0. Esta, traz em seu esteio a cultura do learning by doing, que significa aprender fazendo, da cultura maker, a qual caminha "par-e-passo" com a visão do DIY (Do It Yourself), isto é, faça você mesmo. O modelo entende que o uso irrestrito dos recur-sos tecnológicos visando a interação irá proporcionar o desenvolvimento da coletividade a partir das con-tribuições mútuas e coletivas, estimulando a criatividade e as competências socioemocionais.

Himmetoglu et al., (2020) destacam que "a Educação 4.0 pode ser vista como um novo paradigma que reinterpreta os conceitos como aprendizagem, aluno, professor e escola, de acordo com as necessida-des da Indústria 4.0”.

Percebe-se que, para tudo isso funcionar, há a necessidade da existência de repositórios para a Gestão do Conhecimento, uma vez que há uma quantidade enorme de dados e informações que carecem de tra-tamento para poderem se tornar conhecimento, tornando-se assim um produto portador de valor que gere vantagem competitiva.

A Gestão do Conhecimento tem por finalidade capturar o conhecimento e disponibilizá-lo à organiza-ção, permitindo a democratização e a facilitação do acesso ao conteúdo. A escola, como organização, de-ve perceber que "a criação do conhecimento organizacional deve ser entendida como um processo que "organizacionalmente" amplifica o conhecimento criado pelos indivíduos e o cristaliza no nível do grupo através do diálogo, discussão, compartilhar de experiência, fazer sentido ou comunidade de prática." (Ta-keushi \& Nonaka, 2008).

Por outro lado, temos a tecnologia militar que vem evoluindo de acordo com o tempo. Desde os con-flitos mais simples, no uso de armas rudimentares e do combate corpo-a-corpo, aos ataques nos quais o uso da robótica, das comunicações, da telemetria, permite que um avião possa ser remotamente conduzido por um piloto, dentro de uma sala localizada à mais de $5000 \mathrm{~km}$ do alvo. Entretanto, para operar desta forma, este profissional carece de uma educação muito mais tecnológica, uma vez que os meios utilizados fazem uso desta tecnologia

Observa-se que estamos num avançado estágio evolutivo e que a necessidade da atualização é cons-tante. O presente estudo visa apresentar, inicialmente, uma fundamentação teórica da Educação 4.0, da Indústria 4.0, da Gestão do Conhecimento e da Evolução Educacional-tecnológica no Exército Brasileiro, passando pela metodologia adotada para o estudo, uma discussão acompanhada de uma breve conclusão.

\section{Metodologia}

A metodologia utilizada reveste-se de uma pesquisa descritiva e envolve uma abordagem exploratória, uma vez que visa proporcionar maior familiaridade com o tema e torná-lo evidente. Segundo Bhat-tacherjee (2012), esse é um tipo de abordagem frequentemente utilizado em novas áreas de investigação objetivando determinar a magnitude ou extensão de um fenômeno, problema ou comportamento específico. Desta forma, o primeiro passo foi consolidar uma lista com os tópicos Industria 4.0, Educação 4.0, Educação Militar, Gestão do Conhecimento. O passo seguinte foi a combinação entre elas.

As principais fontes utilizadas para o desenvolvimento deste artigo foram retiradas das seguintes bases: Google Acadêmico, Portal de Periódicos da Capes e Emerald Insight.

Face à temática possuir algumas especificidades, tais como o Ensino Militar e, e em virtude da Indústria 4.0 ter impactos significativos em diversos setores como as indústrias, o comércio, as questões sociais, dentre outras, as consultas não 
se ativeram apenas aos periódicos, mas foram estendidas aos sítios corporativos, governamentais, e demais sítios julgados úteis e pertinentes na colaboração da consecução da pesquisa. Foi dada preferência às publicações a partir de 2017.

\section{Referencial Teórico}

O presente desenvolvimento tratará exclusivamente da fundamentação teórica, estando divido em quatro subtópicos, a saber: Educação 4.0, Indústria 4.0, A Evolução Educacional-Tecnológica no Exército Brasileiro e, a Gestão do Conhecimento.

\subsection{Educação 4.0}

Para chegarmos à educação 4.0, necessitamos conhecer as "educações" que nos sucederam. Na Educação 1.0, o mestre, em virtude de sua erudição, era o centro do processo educacional. Os alunos, neste período, procuravam e escolhiam um mestre para estudar e ficavam sentados aos seus pés "numa atitude de admiração e submissão" (Fava, 2014). Este período durou até meados do século XVIII.

A Educação 2.0, sob forte influência da Revolução Industrial, no final do século XVIII, deu início à educação em massa. A padronização da indústria originou a especialização, vindo a refletir na escola. Esta, passou a focar nas disciplinas, professores e conteúdos especializados. Tais ações acabaram por dificultar a concatenação dos conteúdos, por parte dos alunos, deixando-os fragmentados. E a especialização originou a centralização que se reflete na escola, a qual concentrou tudo na sala de aula, local onde "[...] o mestre repassa para seus aprendizes todo o conhecimento necessário para que tenham sucesso pessoal e profissional na área escolhida" (Fava, 2014). Caracterizava-se pela memorização.

No final dos anos 90, com o desenvolvimento da Internet, ocorre o nascimento da Educação 3.0. A Internet franqueou o acesso às pessoas de forma a se conectarem e se relacionarem de maneira dinâmica. Isso gerou uma ânsia por "[...] trabalhar, compartilhar, interagir, comunicar, ensinar, estudar, aprender" (Fava, 2014). É o surgimento da era digital. Os conteúdos são mediados de forma híbrida onde as atividades ocorriam de forma presencial ou não.

Finalmente chegamos à Educação 4.0. Para Fuhr (2019), com o surgimento da $4^{a}$ Revolução Industrial, a educação se vê inserida em um novo paradigma no qual a informação encontra-se acessível de forma horizontal e circular, sem limitação de tempo ou espaço geográfico. "O papel do educador é o de um curador de múltiplas informações junto ao educando", em que procura organizar e sintetizar a informação, transformando a mesma em conhecimento, e este, em sabedoria.

É perceptível que nesta nova forma de abordagem educacional, o professor não é mais o centro do processo, passando a ser um ator motivador e orientador na estruturação do processo ensino-aprendizagem do discente. Esta ação se dá em todos os níveis educacionais, uma vez que as novas gerações já nascem inseridas em ambientes tecnológicos com aparelhos do tipo "smart" (smartwatch, smartv, smartphone, etc.) convivendo desde a tenra idade com os avanços tecnológicos. É a geração Alpha ou M (de Mobile), formada por crianças nascidas após 2010. Não obstante, as gerações Z (2000 a 2010), Y (1985 a 2000) e X (1965 a 1984), também acabaram se inserindo no ambiente altamente conectados. A Geração X, pela necessidade de não ser ultrapassada pelas modernidades tecnológicas, acabou por aprender a utilizar a tecnologia oferecida e, as Gerações $\mathrm{Y}$ e $\mathrm{Z}$, por fazerem parte deste processo evolutivo, acabaram por dominar o ambiente do ciberespaço.

As novas abordagens e paradigmas nesta forma de educação ciberconectada navega no desenvolvimento de competências que permitam uma interconexão entre conhecimentos e habilidades pessoais, os discentes são instados a se tornarem autores do seu próprio momento. Os ambientes tornam colaborativos e coletivos, de forma que todos possam cocriar um conhecimento seja de maneira on-time, isto é, coletivamente, ou construindo-o aos poucos em momentos estanques, isto é, de forma colaborativa. Neste escopo, a comunicação e interação devem ser intensas, uma vez que a construção se dá de forma holística. 
Dentro desta concepção, Fuhr (2019) complementa afirmando que "o educando nesse ambiente ciberarquitetônico torna-se o ator, o autor do conhecimento por meio da pesquisa proposta nos projetos interdisciplinares que possibilitam o desenvolvimento de competências e habilidades para corresponder à sociedade 4.0”.

Face às transformações existentes no âmbito escolar, - sejam elas de qualquer nível - este consegue fornecer conhecimento mais contextualizado, formando pessoas que atendem às demandas da sociedade atual. A interação pode ser mais bem mantida a partir do momento em que os meios para se realizar o compartilhamento do conhecimento seja aderente à realidade daqueles discentes. Então, o uso de gadgets altamente conectados e a inclusão da gamificação pode ser um forte atrativo para o público mais jovem e intensamente conectado às redes.

Este ambiente permite que a transmissão de conhecimento se torne mais efetiva, criando um diferencial para as escolas que adotam esse método, uma vez que os resultados positivos são nítidos. Desta forma, o aluno ganha liberdade para produzir conhecimento de acordo com os seus interesses reais, por meio do uso das metodologias ativas e atuais de aprendizagem. Entretanto, para que este sucesso ocorra, é fundamental que os professores, que passarão a atuar como mediadores deste processo ensino-aprendizagem, estejam preparados para o uso destas novas tecnologias e formas de interação.

Por fim, são esperados que os discentes também se adequem à esta nova sistemática, mudando percepções e paradigmas, compreendendo a necessidade de haver colaboração, compreensão e comunicação entre as pessoas para se chegar a um senso comum. Além disso suas habilidades socioemocionais, as conhecidas soft skills, surgem com destaque nesta nova forma de educação, uma vez que estas habilidades coadunam com os atributos esperados na Educação 4.0, tais como a comunicação, o pensamento crítico, a capacidade de lidar com problemas complexos, a rápida tomada de decisões e a empatia.

\subsection{Indústria 4.0}

A Industria 4.0, originalmente, foi concebida dentro de um contexto manufatureiro, entretanto, face às suas inúmeras potencialidades, ela extrapolou o processo produtivo sendo utilizada nas mais diversas áreas, tais como healthcare, indústria, telecomunicações, engenharia, transporte, agropecuária, militar, dentre outras.

Para entendermos como chegamos a este momento, carecemos conhecer os antecedentes históricos desta revolução.

A primeira revolução industrial, também nominada Industria 1.0 teve seu início em 1760 durando até 1840. Ela deu início à produção mecânica, motivada principalmente pela construção das ferrovias e pela invenção da máquina a vapor. Com o advento da energia a partir do carvão surgiram as primeiras formas de Indústrias automatizadas. Este movimento fez com que a produção manufatureira e artesanal.

A segunda revolução industrial, ou Industria 2.0, foi iniciada na segunda metade do século XIX e se caracterizou pela produção em massa e pelo surgimento da linha de montagem e pelo uso da eletricidade nas fábricas. São criados o motor à explosão, a produção do aço e alumínio e a invenção do Telégrafo. Surge nesta época o Fordismo e o Taylorismo.

Na década de 1960 surge a terceira revolução industrial ou Indústria 3.0, também conhecida como revolução digital ou do computador. Foi uma revolução técnico-científica e informacional. As áreas da robótica, nanotecnologia, biotecnologia, telecomunicações, dentre outras, tiveram grande crescimento. O surgimento da Internet foi outro fator de destaque neste período.

Schwab (2016) cita que:

Ao permitir "fábricas inteligentes", a quarta revolução industrial cria um mundo onde os sistemas físicos e virtuais de fabricação cooperam de forma global e flexível. Isso permite a total personalização de produtos e a criação de novos modelos operacionais. [...] O que torna a quarta revolução industrial fundamentalmente diferente das anteriores é a fusão dessas tecnologias e a interação entre os domínios físicos, digitais e biológicos.” (Schwab, 2016). 
Quando abordamos o tema da Indústria 4.0, é fundamental mencionarmos seus impulsionadores tecnológicos:

- Internet das Coisas (IOT - Internet Of Things): Segundo Madakam et al., (2015), a IoT é uma revolução tecnológica que representa o futuro da computação e das comunicações, e seu desenvolvimento depende da inovação técnica dinâmica em vários campos importantes, de sensores sem fio a nanotecnologia. Eles vão marcar cada objeto para identificar, automatizar, monitorar e controlar. E segue citando que:

"Na chamada Internet das Coisas, sensores e atuadores embutidos em objetos físicos - de estradas a marcapassos - são conectados por redes com e sem fio, geralmente usando o mesmo IP de Internet que conecta a Internet. Essas redes produzem grandes volumes de dados que fluem para os computadores para análise. Quando os objetos podem sentir o ambiente e se comunicar, eles se tornam ferramentas para compreender a complexidade e responder a ela rapidamente. O que é revolucionário em tudo isso é que esses sistemas de informação físicos agora estão começando a ser implantados, e alguns deles funcionam em grande parte sem intervenção humana.” (Mandakam Et al., 2016).

- Inteligência Artificial (IA): De acordo com o sítio do Aires et al. (2019):

... o conceito de Inteligência Artificial (IA) se refere a uma solução digital (software) que simula o funcionamento da inteligência humana para executar determinadas funções. É comum encontrar o termo fazendo referência também ao campo de estudos e desenvolvimento desse tipo de tecnologia (Aires et al., 2019).

- Realidade Aumentada: De acordo com Simi et al., (2011), a "realidade aumentada é uma tecnologia que faz a integração do meio real com o virtual, promovendo a exposição de elementos virtuais sobre a imagem do ambiente real através da tela de algum dispositivo (celular, computador, tablet, etc.)”.

- $\quad$ Blockchains: Para Fraga-Lamas \& Fernandez-Carames (2019), devido ao grande número de trocas de dados pela Internet, manter a confidencialidade, privacidade e integridade torna-se um grande problema na Indústria 4.0. Lidar com dados em grandes volumes e, portanto, é necessário considerar questões como heterogeneidade de dados, integridade de dados, e redundância de dados junto com a segurança e privacidade (Bodkhe et al., 2020).

- Robôs Autônomos: Para Albertin et al., (2017), “a utilização de robôs autônomos na indústria, também conhecidos como robôs inteligentes ou colaborativos (Cobots), não é um conceito novo pois eles já são utilizados em muitas indústrias para realizar tarefas complexas". Existem pesquisas voltadas à indústria de defesa que fazem uso desta tecnologia. Em Israel há o Dogo, que foi desenvolvido pela empresa General Robotics. Este dispositivo conta com oito câmeras de alta definição, um microfone e alto-falante para permitir negociações com os suspeitos e espaço para carregar uma pistola Glock Compact de $9 \mathrm{~mm}$, que pode ser utilizada para abater ameaças. Ele se move por meio de esteiras similares às de um tanque que podem encarar qualquer tipo de terreno (Meurer \& Lins, 2016). Nos EUA temos o Spot, o cão-robô, desenvolvido pela Boston Dynamics, que já foi utilizado para monitorar Chernobyl (Guizzo, 2019) e pela Marinha Americana. A Samsung desenvolveu o SGR A1 para monitorar as fronteiras das Coreias do Norte e do Sul, que possui a capacidade de detectar alvos de forma autônoma (Wagstaff, 2014).

- Simulação: Trata-se de uma metodologia que visa a utilização de ensaios visando a resolução de problemas existentes. O uso de softwares para a prototipagem virtual vem sendo uma das principais técnicas na Indústria 4.0. As técnicas modulares de simulação e modelagem permitem que as unidades descentralizadas alterem de forma flexível os produtos e, assim, possibilitem uma rápida inovação de produtos (Brettel et al., 2014).

- Impressão 3D: Takagashi (2012) destaca que esta tecnologia permite a verificação e os ajustes das diferentes peças projetadas, muito antes de comprometer a linha produtiva. Além disso, reproduz modelos detalhados em escalas 
menores, representando uma redução nos custos dos projetos. Há ainda a possibilidade da produção de peças substitutas a partir da impressão 3D que permite a materialização de determinada peça com o mínimo desperdício.

- Redes de Sensores Sem Fio: De acordo com Loureiro et al., (2003), as redes de sensores sem fio vêm sendo objeto de estudo já há algum tempo, principalmente devido às inovações tecnológicas introduzidas pelo avanço nos sistemas micro-eletro-mecânicos, as comunicações sem fio e a eletrônica digital. Seu princípio consiste no uso de uma certa quantidade de nós sensores, sujeitos a falhas, e com interligação sem fio entre eles. Tais sensores devem ser de baixo custo, baixo consumo e pequenos no tamanho.

- $\quad$ Computação em Nuvem: Sacomano et al., (2018) citam que a computação em nuvem é fundamental para que as informações e dados possam ser acessadas, de forma fácil, de qualquer parte do mundo em que haja internet, para controle multilocal do processo produtivo ou outro que se fizer necessário.

- Cibersegurança: Para Azambuja \& Almeida (2021), "na era da Indústria 4.0, com a presença dos sistemas ciberfísicos conectados em ambientes industriais, surgem os desafios da Segurança Cibernética (SegCiber)”. Os ataques cibernéticos podem gerar prejuízos financeiros e impactos na imagem da empresa (Lezzi et al., 2018). A Segurança Cibernética é um dos desafios enfrentados pelas empresas inseridas no escopo da Indústria 4.0. O contínuo avançar das tecnologias alavancam as empresas para outro nível no qual os equipamentos estão conectados por meio de redes computacionais internas e externas a empresa. Estas redes requerem a ação da segurança cibernética com vias a protegêlas dos ataques cibernéticos, os quais estão cada dia mais presentes no espaço cibernético (WU et al., 2018).

- Big Data: O sítio da Harbor Informática Industrial destaca que o Big Data é um termo voltado para o tratamento de grandes volumes de informações, sendo fundamental para a IoT em virtude dos dados colhidos pelos seus sensores (Harbor, 2018).

Ge et al., (2018) ressaltam que o gerenciamento de qualidade Big Data é crítico para os aplicativos de IoT, especialmente para a análise de dados. Neste diapasão, não há como negar que as aplicações da tecnologia de Big Data podem melhorar a vantagens competitivas de empresas e organizações. Desta forma, o Big Data se torna efetivamente um importante ativo para as empresas permitindo gerar vantagens na competitividade do mercado (Lai, 2017).

\subsection{Evolução Educacional - Tecnológica no Exército Brasileiro}

Como todo processo evolutivo, o ensino no Exército teve seu primeiro período ocorrido entre 1699 e 1808 , caracterizando-se pela precariedade e a improvisação do ensino.

Pirassinunga (1958) menciona que o primeiro vestígio do ensino militar ocorreu em 1698, no Rio de Janeiro, nas lições mandadas dar aos contestáveis e Artilheiros dessa Praça, sobre uso e manejo da artilharia.

Após a chegada da Corte Portuguesa, vislumbrou-se a necessidade de uma restruturação do Exército, proporcionando-lhe a eficácia no combate e rompendo o laço com o amadorismo no qual encontrava-se imerso. Nesta segunda fase, ocorreu a criação da Real Academia Militar, em 4 de dezembro de 1810, com os cursos de Engenharia e cursos eminentemente militares.

Em 1858 surgiram os primeiros cursos preparatórios, visando dar condições intelectuais àqueles que desejassem ingressar no Exército. Primeiramente no Rio de Janeiro e, posteriormente em Porto Alegre, tornando-se os embriões do ensino secundário militar. 
Em 1913 é criada a Escola Militar do Realengo, no Rio de Janeiro, que tem seu funcionamento até 1944 quando, diante da necessidade de aperfeiçoar a formação de oficiais para um exército que crescia e se operacionalizava, foi criada a Academia Militar das Agulhas Negras, em Resende - RJ.

Atualmente, o Exército possui, além do Instituto Militar de Engenharia, que é vinculado ao Departamento de Ciência e Tecnologia do Exército, diversas Escolas Militares nos mais variados níveis educacionais, desde o ensino fundamental e médio, passando pelo tecnólogo, direcionado à formação dos Sargentos, ao superior, voltado à formação dos Oficiais, oferecendo cursos de pós-graduação “lato” e "strictu” sensu até o nível Doutorado.

Nogueira (2014) cita que no decorrer dos anos, durante cada momento observado, as instituições passaram por diversas reformas visando a sua adequação do ensino militar às novas demandas da profissionalização militar. Quer seja no rearranjo das instruções e na adoção de metodologias estrangeiras, seja alemã (jovens turcos), francesa ou americana, o Exército sempre buscou a sua atualização doutrinária.

\subsection{Gestão do Conhecimento}

Neto (2012) e Nonaka e Takeuchi (2009) explicam que a essência da gestão do conhecimento está na disposição das pessoas para compartilhar suas experiências, havendo possibilidades de conversão entre as distintas expressões do conhecimento:

- Socialização (tácito de um indivíduo para outros),

- Explicitação, materializando conhecimentos tácitos em diferentes documentos,

- Combinação (conhecimento explícito de um indivíduo para o grupo);

- Apropriação, identificando as experiências dos colaboradores para aprendizagem e aplicação nas organizações.

Para Severiano Junior et al., (2021), cita que "as organizações vivem num mundo de incertezas, rodeadas de ambientes em constante mudanças, num mercado muito competitivo. Para combater esse paradigma é necessário aproveitar o capital humano, uma vez que o recurso mais valioso nas organizações são as pessoas. [...] A gestão de conhecimento surge como uma estratégia que pode ser utilizada pela organização com vista à prossecução dos objetivos, ajustando o conhecimento aos recursos existentes.”

É notória a grande presença das tecnologias e das mídias no nosso cotidiano, realizando mudanças na construção do conhecimento. Deste modo, a sociedade se viu compelida a acompanhar essa nova relação estabelecida com todas as fontes de conhecimento, transformando amplamente as relações do ser humano com as informações e com os próprios processos de ensino e aprendizagem. (Malaggi \& Vitor, 2012).

Ospennikova et al., (2015), destacam que o ensino deve se concentrar na formação do conhecimento, das habilidades e das competências, permitindo que as novas gerações sejam integradas com sucesso aos sistemas sócio-técnicos modernos, para manter e desenvolver eficientemente o potencial científico e tecnológico da sociedade.

A estratégia da gestão do Conhecimento deveria ser utilizada em instituições acadêmicas e educacionais, relacionadas à produção de conhecimento (Cunha et al., 2019). Na visão de Petrova et al., (2015) e Severiano Junior et al., (2021) a pesquisa universitária adota a ideia da universidade clássica tradicional associada a esta produção. Ressalta a infinitude neste processo, em que todas as partes relacionadas precisam ser motivadas constantemente, garantindo o seu funcionamento de forma permanente e intensa. 
A motivação constante visa que alunos renovem seus desafios de forma a buscar, sempre, uma nova solução para os problemas apresentados, (Jakobsone et al., 2017).

\section{Resultados e Discussão}

Ao percebermos que os impulsionadores da Indústria 4.0, estão presentes nas diversas formas de interação e materiais disponíveis para o Emprego Militar, torna-se plausível compreender a importância na adaptação das disciplinas, buscando a implementação de novas metodologias ativas para a construção do conhecimento adquirido e a adquirir.

Caldeira (2018) cita que" na atualidade, o uso de veículos terrestres e aéreos não tripulados e de robôs em operações militares já é uma realidade". No entanto, o Exército Brasileiro já vem testando os Sistemas de Aeronaves Remotamente Pilotadas e o Plano Estratégico do Exército (2020-2023) contempla o desenvolvimento de Sistemas de Veículos Terrestres Remotamente Pilotados (SVTRP) (Rocha \& Fonseca, 2019).

Quando compreendemos a dinâmica existente na Realidade Aumentada e na Inteligência Artificial e as comparamos com o Sistema de Simulação de Apoio de Fogo, é perceptível a presença da realidade aumentada e da simulação, visando o treinamento dos militares:

"O sistema facilita o treinamento em condições que imitam o combate em diversas áreas, como a preparação e a análise de missões, o reconhecimento do terreno, o levantamento de alvos, a preparação e a execução das ordens de tiro, além da observação e de correções do desencadeamento de fogo (Cuperschmid et al., 2015).

O uso de sensores sem fim pode, dentre outros locais, ser bastante comuns e usuais nos depósitos militares, o uso da tecnologia de RFId (Radio Frequency Identification), ou identificação por rádio frequência, a qual possui seu surgimento a partir de uma necessidade de guerra, onde os aviões para não serem atingidos pelos fogos de artilharia amigos, realizavam por meio da troca de sinais de rádio frequência, o chamado IFF (Identify Friend and Foe), isto é, Identificar Amigo ou Inimigo.

A Cibersegurança é fundamental para a manutenção das infraestruturas críticas de um país, principalmente quando há a possibilidade de estarem sob ataques cibernéticos. A guerra cibernética e a espionagem digital são uma realidade, há muito, explorada por diversas nações para obterem vantagem competitiva. O autor Buchanan (2016) destaca a criação, por parte da China, de uma Unidade CyberWar no Exército Popular de Libertação da China.

Nesta mesma linha, Vianna e Camelo (2020) citam que:

"No que se refere a defesa cibernética, o documento da Estratégia Nacional de Defesa dos Estados Unidos, de 2018, reconhece a necessidade de se antecipar aos ataques e enxerga a América como principal alvo no campo cibernético. Também afirma que a área cibernética é prioridade para o governo, garantindo investimentos contínuos para reconstituir e assegurar capacidades cibernéticas em todo espectro das operações militares, transformando o espaço cibernético em um domínio de combate" (Vianna \& Camelo, 2020).

Em outro estudo, Pinto e Grassi (2020) destacam como os EUA conseguiram desabilitar, por meio do ataque cibernético, as redes elétricas da Rússia.

\footnotetext{
"Segundo autoridades governamentais norte-americanas, os EUA obtiveram acesso a rede elétrica russa, demonstrando como o Cyber Command irá se posicionar diante de ameaças cibernéticas no futuro. Segundo as fontes do jornal, os EUA conseguiram infiltrar a infraestrutura energética russa a ponto de desabilitá-la em caso de ações contra os Estados Unidos", (Pinto \& Grassi, 2020).
}

Deste modo, o Brasil, por intermédio do Comando de Defesa Cibernética contrapõem-se a estes tipos de ataques, 
qualificando seu pessoal para atuar neste ambiente de guerra digital.

Atuando como um enorme mainframe, o BigData, dentro da área militar, torna-se fundamental para o suporte às diversas áreas existentes, permitindo o armazenamento de uma enorme variedade de dados. A manutenção da sua operabilidade é essencial para o sucesso das inúmeras missões e ações nas quais a Força Terrestre está direta ou indiretamente conectada. Em conjunto, cabe ressaltar a importância da computação em nuvem, a qual permite a possibilidade de acesso remoto em qualquer lugar a partir de determinados dispositivos. Isto gera dinamismo e capilaridade das informações proporcionando a continuidade das operações em qualquer faixa do terreno.

Diante de todas estas tecnologias cabe-nos compreender que a Gestão do Conhecimento surge como um organizador de conteúdo, permitindo que, de forma coletiva ou colaborativa, possamos compartilhar o conhecimento.

De acordo com Aires et al., (2018), o seu objetivo deve ser o de movimentar a organização para o conhecimento, e este cumprir seu papel de proporcionar mudanças inovadoras capazes de diferenciar a organização de seus concorrentes. Burslaff \& Bartelt (2017) ressaltam a importância de uma arquitetura baseada no conhecimento de forma a garantir que o conhecimento seja reutilizável, pois esta é uma tendência no contexto da Indústria 4.0. A aprendizagem organizacional e dos indivíduos surge como fator crítico a ser gerenciado para uma gestão mais eficiente e que contribua para a construção de vantagens competitivas (Stocker et al., 2014).

\section{Considerações Finais}

Neste breve artigo, tivemos a oportunidade de compreendermos a importância e a abrangência da Indústria 4.0 no escopo de uma sociedade conectada, a qual carece da existência de uma educação que acompanhe e compreenda as novas tendências ciberculturas nas quais o mundo está inserido. Desta forma, a concepção da ideia de uma Educação 4.0 é primordial para que os docentes e discentes compreendam as evoluções e se insiram nestas, tornando-se partícipes deste momento colaborativo e coletivo na construção do conhecimento compartilhado.

$\mathrm{Na}$ continuidade, destacamos a necessidade de que o Exército Brasileiro, por meio de seus estabelecimentos de ensino estejam inseridos na concepção da Educação 4.0, uma vez que uma diversidade de ações e equipamentos utilizados pela Força Terrestre estão inseridos no espectro da Indústria 4.0, logo, sendo necessária a adaptação de docentes e discentes ou, no jargão militar, de Instrutores e Instruendos às temáticas abrangidas pela Educação 4.0

Relatamos a importância de que todo este processo seja alicerçado pela sistemática repositória da Gestão do Conhecimento permitindo, num primeiro momento, reunir os conhecimentos existentes de forma que não haja perda de continuidade no processo cognitivo. Além disso, esta forma de Gestão permite dinamizar a troca de informações consentindo que a participação dos atores ocorra de forma coletiva, isto é "on-time", e/ou colaborativa, onde cada um interage da maneira que melhor lhe convier.

Por fim, é importante ressaltar que a educação 4.0 vem se tornando uma necessidade premente nas diversas áreas do saber. As profissões perpassaram a necessidade básica do conhecimento, carecendo uma maior gama de informações, ações, comportamentos e relacionamentos individuais e coletivos para o correto desempenho de suas atividades. Não obstante, o Exército Brasileiro finda por demandar estas mesmas necessidades visando a propagação do conhecimento para a consecução dos seus objetivos institucionais e profissionais. Como sabiamente afirmou o autor romano Vegécio, "Si vis pacem, para bellum", isto é, se queres a paz, prepara-te para a guerra. E, para uma preparação de excelência, nada melhor do que uma educação de ponta. 


\section{Referências}

Aires, C. S. F., Almeida, G. J., \& Silveira, S. O. (2019). Inteligência Artificial na Gestão de Estoque. Fateclog, 1, 1-7.

Aires, R. W. do A., Moreira, F. K., \& Freire, P. de S. (2018). Indústria 4.0: desafios e tendências para a gestão do conhecimento. Revista E-Tech: Tecnologias Para Competitividade Industrial 11(1), 67-87. https://doi.org/10.18624/e-tech.v11i1.988.

Albertin, M. R., Elienesio, M. L. B., Aires, A. D. S., Pontes, H. L. J., \& Junior, D. P. A. (2017). Principais inovações tecnológicas da indústria 4.0 e suas aplicações e implicações na manufatura. XXIV Simpósio de Engenharia de Produção. Anais..., Bauru.

Azambuja, A. J. G. de, \& Almeida, V. R. (2021). A bibliometric study of Cybersecurity in Industry 4.0 publications. Research, Society and Development, 10(3), 4210312937e. https://doi.org/10.33448/rsd-v10i3.12937.

Bhattacherjee, A. (2012). Social science research: Principles, methods, and practices. Scholar Commons, University of Florida.

Bitkom, V. D. M. A. ZVEI. 2016. "Implementation Strategy Industrie 4.0: Report on the Results of the Industrie 4.0 Platform.". https://www.zvei.org/fileadmin/user_upload/Presse_und_Medien/Publikationen/20, 16.

Bodkhe, U., Tanwar, S., Parekh, K., Khanpara, P., Tyagi, S., Kumar, N., \& Alazab, M. (2020). Blockchain for industry 4.0: A comprehensive review. IEEE 10.1109/ACCESS.2020.2988579.

Buchanan, B. (2016). The cybersecurity dilemma: Hacking, trust, and fear between nations. Oxford University Press.

Burzlaff, F., \& Bartelt, C. (2017, April). Knowledge-driven architecture composition: Case-based formalization of integration knowledge to enable automated component coupling. In 2017 IEEE International Conference on Software Architecture Workshops (ICSAW) (pp. 108-111). IEEE.

Caldeira, A. B. (2018). Sistemas Mecatrônicos e a guerra do futuro.

Cunha, D. O., Oliveira, F. L., Bezerra, L. F., Severiano Junior, E., \& Gonçalves, C. P. (2019). O Uso do E-Learning como Ferramenta de Ensino e Aprendizagem. Revista de Tecnologia Aplicada, 8(3), 41-53. 21714/2237-3713rta2019v8n3p4153

Cuperschmid, A. R. M., Amorim, J. A., Matos, C. E. A., \& Einstein, A. (2015). Uso de Realidade Aumentada para o Treinamento Militar. Revista Militar de Ciência e Tecnologia, 3, 5-17.

Fava, R. (2014). Educação 3.0: aplicando o PDCA nas instituições de ensino. Saraiva, 256.

Fraga-Lamas, P., \& Fernández-Caramés, T. M. (2019). A review on blockchain technologies for an advanced and cyber-resilient automotive industry. IEEE access, 7, 17578-17598.

Führ, R. C. (2019). Educação 4.0 nos impactos da quarta revolução industrial. Appris.

Ge, M., Bangui, H., \& Buhnova, B. (2018). Big data for internet of things: a survey. Future generation computer systems, 87, 601-614.

Guizzo, E. (2019). By leaps and bounds: An exclusive look at how boston dynamics is redefining robot agility. IEEE Spectrum, 56(12), 34-39.

Himmetoglu, B., Aydug, D., \& Bayrak, C. (2020). Education 4.0: Defining the teacher, the student, and the school manager aspects of the revolution. Turkish Online Journal of Distance Education, 21(Special Issue-IODL), 12-28.

Jakobsone, A., Cakula, S., \& Florea, M. (2017). Modelling of knowledge sharing for the provision of sustainable cooperation between adult educational institutions and enterprises. Procedia computer science, 104, 160-165.

Lai, S. T. (2017). An Iterative and Incremental Data Quality Improvement Procedure for Reducing the Risk of Big Data Project. J. Softw., 12(12), 945-956.

Lezzi, M., Lazoi, M., \& Corallo, A. (2018). Cybersecurity for Industry 4.0 in the current literature: A reference framework. Computers in Industry, 103, 97110 .

Loureiro, A. A., Nogueira, J. M. S., Ruiz, L. B., Mini, R. A. D. F., Nakamura, E. F., \& Figueiredo, C. M. S. (2003, May). Redes de sensores sem fio. In Simpósio Brasileiro de Redes de Computadores (SBRC) (pp. 179-226). sn.

Madakam, S., Lake, V., Lake, V., \& Lake, V. (2015). Internet of Things (IoT): A literature review. Journal of Computer and Communications, $3(05)$, 164.

Malaggi, V., \& Marcon, K. (2012). Cibercultura e Educação: algumas reflexões sobre processos educativos na sociedade tecnológica contemporânea. Revista espaço acadêmico, 11(132), 115-123.

Meurer, R., \& Lins, H. N. (2016). Grandes eventos esportivos e turismo: Destaque para a Copa do Mundo de 2014. Planejamento e Políticas Públicas, (47).

Neto, I. R. (2012). Gestão do conhecimento e complexidade. Revista de Gestão e Projetos, 3(1), 94-126.

Ospennikova, E., Ershov, M., \& Iljin, I. (2015). Educational robotics as an inovative educational technology. Procedia-Social and Behavioral Sciences, 214, $18-26$.

Petrova, G. I., Smokotin, V. M., Kornienko, A. A., Ershova, I. A., \& Kachalov, N. A. (2015). Knowledge Management as a Strategy for the Administration of Education in the Research University. Procedia-Social and Behavioral Sciences, 166, 451-455.

Pinto, D. J. A., \& Grassi, J. M. (2020). Guerra cibernética, ameaças às infraestruturas críticas e a defesa cibernética do Brasil. Revista Brasileira de Estudos de Defesa, 7(2). 
Research, Society and Development, v. 10, n. 10, e189101018867, 2021

(CC BY 4.0) | ISSN 2525-3409 | DOI: http://dx.doi.org/10.33448/rsd-v10i10.18867

Pirassinunga, A. S. (1958). O ensino militar no Brasil: período colonial. Biblioteca do Exército.

Rocha, M., \& da Fonseca, D. F. (2019). A Questão Cibernética e o Pensamento Realista. Revista da Escola de Guerra Naval, 25(2).

Sacomano, J. B., Gonçalves, R. F., Bonilla, S. H., da Silva, M. T., \& Sátyro, W. C. (2018). Indústria 4.0. Editora Blucher.

Severiano Junior, E., Cunha, D. O., Zouain, D. M., \& Gonçalves, C. P. (2021). Produtivismo Acadêmico e suas Consequências para a Produção Científica na Área de Administração. REAd. Revista Eletrônica de Administração, 27(2), 343-374.

Simi, S. K., Dias, W. D. J., de Araújo, S. A., \& Alves, W. A. L. (2011). Usando realidade virtual e aumentada no resgate e valorização de jogos populares antigos. Exacta, 9(2), 267-272.

Stocker, A., Brandl, P., Michalczuk, R., \& Rosenberger, M. (2014). Mensch-zentrierte IKT-Lösungen in einer Smart Factory. e \& i Elektrotechnik und Informationstechnik, 131(7), 207-211.

Takeuchi, H., \& Nonaka, I. (2009). Gestão do conhecimento. Bookman Editora.

Wagstaff, K. (2014). Future tech? Autonomous killer robots are already here-NBC news. NBC News, 14.

Wu, D., Ren, A., Zhang, W., Fan, F., Liu, P., Fu, X., \& Terpenny, J. (2018). Cybersecurity for digital manufacturing. Journal of manufacturing systems, 48, 3 12 . 